\title{
Systematic analyses of train run deviations from the timetable
}

\author{
T. Richter \\ Operations Quality and Monitoring, Rail Net Denmark, Denmark
}

\begin{abstract}
On Rail Net Denmark's network, a Delay Report is created if a train is delayed more than 4 minutes and 59 seconds. All delayed trains are attached to a Delay Report describing the cause and consequences of the incident. The Punctuality Reporting System focuses on the causes of initial delays and much effort is spent analysing those. However, until now, much less effort has been spent on systematically analysing the train running themselves, extracting information on where in the network trains are delayed and which trains are delayed. After a description of the present delay follow-up system and its systemic weakness (section 3 and section 4), a toolbox of analytical methods developed to deal with this weakness is presented. The methods use a percentile approach aggregating either deviation from the timetable at measuring points or difference in deviation between measuring points. The aim is to identify the measuring points where the largest delays occur for individual trains and train systems so that the parties responsible can act. After a description of the methods (section 5), examples of the new types of analysis are demonstrated (section 6), e.g. identification of local speed restrictions which influence the punctuality, the worst performing trains and reasons for their delays. It is thus shown how new information can be extracted from the train run history. The percentile approach is orthogonal to the classical analysis of cause of delay above a threshold and should not be regarded as a substitute but as a valuable supplement. One of the reasons for the successful implementation is a general shift in the corporate mindset within Rail Net Denmark towards a higher KPI focus.
\end{abstract}

Keywords: railway operations, systematic follow-up, delay, punctuality, service quality, robustness, realised operations, organisational implementation. 


\section{Introduction}

The results of measurements depend on how the measuring is carried out as well as on how data is aggregated. Traditionally, all analysis of train delays within the Danish railway sector has been based on the notion of affected train, which are trains delayed more than 4 minutes and 59 seconds or cancelled. This is the method recommended by UIC [1]. Within this definition, a train is either affected or it is punctual. Thus lots of information about delays smaller than the threshold of affected trains has not been systematically analysed - until now.

\section{Operation of Rail Net Denmark in brief}

As in many other EU countries the railway sector in Denmark has been divided into separate Infrastructure Managers (IM) and Railway Undertakings (RU). Rail Net Denmark is the main IM in Denmark and five major passenger RU operate on the network of Rail Net Denmark. Passenger transport is far more important than freight transport in Denmark, which is limited to three major freight RU operating mostly transit trains between Sweden and the European continent.
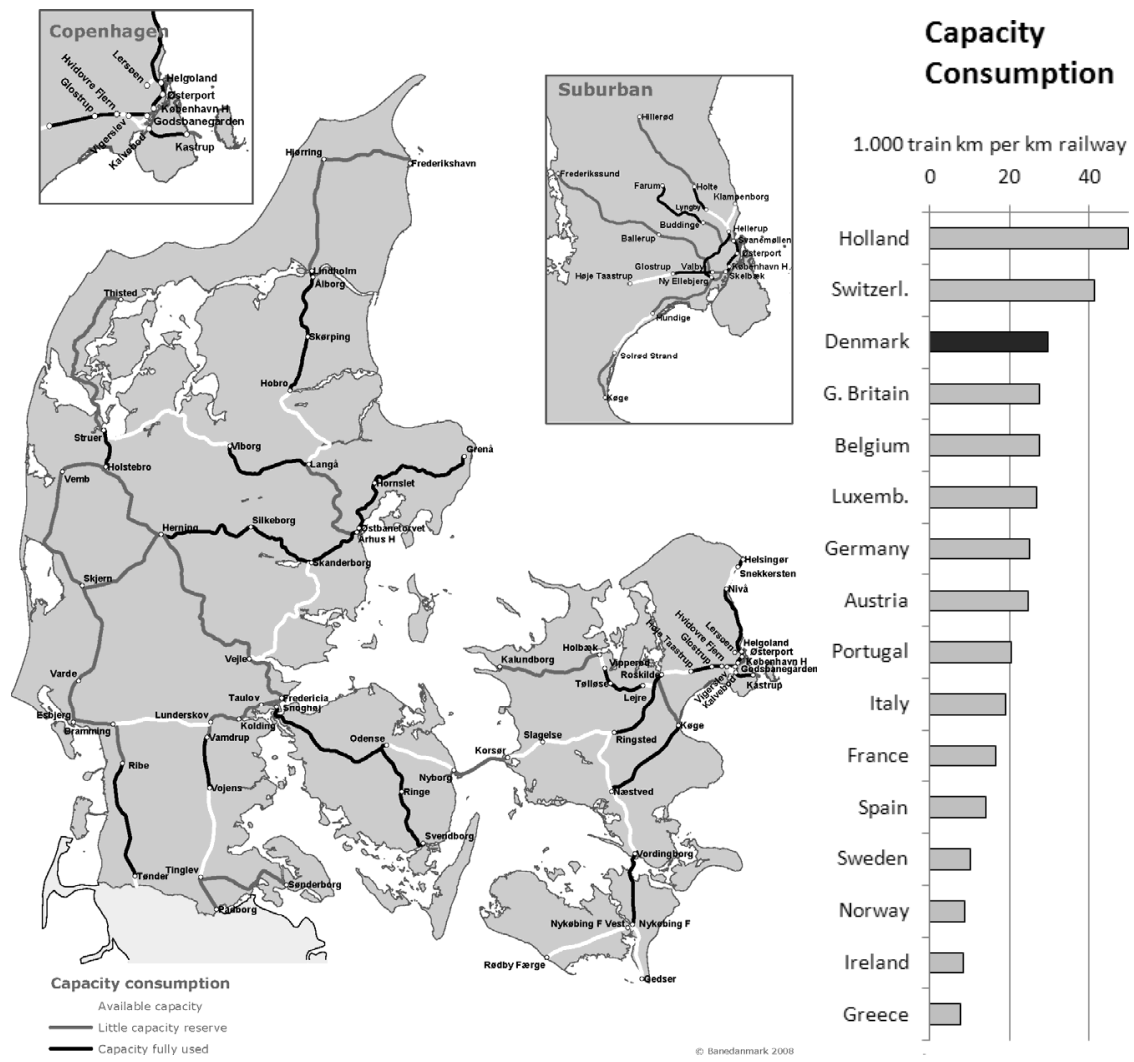

Figure 1: Capacity consumption in Denmark in 2008 [2] and in Europe [3]. 
The length of Rail Net Denmark's network is 2,220 km of which $45 \%$ are double or quadruple track. On the mainline network, approximately 1,400 trains are operated daily of which approximately 70 are freight trains. The length of the Copenhagen suburban railway network is $169 \mathrm{~km}$ and approximately 1,100 trains are operated daily on this network [4].

The network of Rail Net Denmark is one of the most densely used in Europe following Switzerland and the Netherlands (cf. figure 1). Using the definitions of UIC leaflet 406 [5] in Figure 1, the capacity consumption is at the limit or near the limit on parts of the network. Such intense usage of a railway network makes it prone to delays and initial delays may very well cause consecutive delays. This also raises the risk that minor timetabling faults or local temporary infrastructure shortcomings have larger consequences. Thus detailed and advanced analysis of train delays are important in order to achieve a reasonable punctuality.

\section{Available data: how delays are measured}

The backbone of the Punctuality Reporting System of Rail Net Denmark is train position data from the digital Traffic Management Systems (TMS), which cover $70 \%$ of the length of the network. The data collected are arrival times to and departures time from measuring points, which are stations and halts. The arrival time is defined as the time when the platform track circuit is occupied and departure time is defined as the time when the next main track circuit is occupied. On the parts of the network where older and less capable TMS are used, arrival and departure times are entered manually and only for the main stations. Approximately 330 measuring points exist of which 166 automatically collect data from the TMS. Based on this information as well as the timetable, RDS creates a train run history (Table 1).

Table 1: $\quad$ Train run history.

\begin{tabular}{|c|c|c|c|c|c|c|c|c|c|c|c|}
\hline TOG & FORSTE_KOREDATO & STAT & MLD_TYP & PLANTID & MLD_KAT & AFVIGELSE & MELDINGSKILDE & TRA_ARS & ARS_TOG & TEKST & DRAP \\
\hline 136 & $23-07-2008$ & 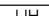 & 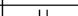 & $23-07-200011.00$ & $k$ & 0 & INDOAT? & & & & \\
\hline 136 & $23-07-2008$ & $\mathrm{AB}$ & 1 & $23-07-200811 \cdot 06$ & K & 0 & INDDAT2 & & & & \\
\hline 136 & $23-07-2008$ & $\mathrm{AB}$ & $\mathrm{U}$ & $23-07-200811: 10$ & $\mathrm{k}$ & -17 & INDDAT2 & 920 & & & \begin{tabular}{|l|}
941815 \\
\end{tabular} \\
\hline 136 & $23-07-2008$ & $\mathrm{EH}$ & G & $23-07-200811: 23$ & K & -15 & INDDAT2 & & & & \\
\hline 136 & $23-07-2008$ & $S \emptyset$ & I & $23-07-200811: 32$ & $\mathrm{k}$ & -15 & INDDAT2 & & & & \\
\hline 136 & $23-07-2008$ & $s \emptyset$ & $\frac{1}{U}$ & $23-07-200811: 33$ & $\mathrm{~K}$ & -15 & INDDAT2 & & & & \\
\hline 136 & $23-07-2008$ & $\mathrm{HB}$ & $\frac{1}{1}$ & $23-07-200811: 50$ & $\mathrm{~K}$ & -13 & INDDAT2 & & & & \\
\hline 136 & $23-07-2008$ & $\mathrm{HB}$ & $\frac{1}{u}$ & $23-07-200811: 51$ & K & -13 & INDDAT2 & & & & \\
\hline 136 & $23-07-2008$ & $\mathrm{RD}$ & 1 & 23-07-2008 12:07 & K & -11 & INDDAT2 & & & & \\
\hline 136 & $23-07-2008$ & $\mathrm{RD}$ & $\mathrm{U}$ & $23-07-200812: 08$ & $\mathrm{~K}$ & -11 & INDDAT2 & & & & \\
\hline 136 & $23-07-2008$ & LG & 1 & 23-07-2008 12:16 & K & -12 & INDDAT2 & & & & \\
\hline 136 & $23-07-2008$ & LG & $u$ & $23-07-200812: 17$ & $\mathrm{~K}$ & -12 & INDDAT2 & & & & \\
\hline 136 & $23-07-2008$ & AR & 1 & $23-07-200812: 47$ & K & -8 & INDDAT2 & & & & \\
\hline 136 & $23-07-2008$ & $\mathrm{AR}$ & $\mathrm{u}$ & $23-07-200812.54$ & $\mathrm{~K}$ & -8 & INDDAT2 & & & & \\
\hline 136 & $23-07-2008$ & $\mathrm{SD}$ & $\frac{1}{1}$ & $23-07-200813: 09$ & $\bar{K}$ & -8 & INDDAT2 & & & & \\
\hline 136 & $23-07-2008$ & SD & $u$ & $23-07-2008$ 13:10 & $\mathrm{k}$ & -8 & INDDAT2 & & & & \\
\hline 136 & $23-07-2008$ & HED & $\mathrm{U}$ & 23-07-2008 13:34 & K & $-5,17$ & $\mathrm{DWH}$ & & & & \\
\hline 136 & $23-07-2008$ & VJ & 1 & 23-07-2008 13:42 & K & $-3,17$ & DWH & & & & \\
\hline 136 & $23-07-2008$ & WJ & $\frac{1}{u}$ & $23-07-200813: 44$ & k & $-4,83$ & $\mathrm{DWH}$ & & & & \\
\hline 136 & $23-07-2008$ & BK & G & $23-07-200813.53$ & K & $-1,5$ & DWH & & & & \\
\hline 136 & $23-07-2008$ & $F A$ & 1 & 23-07-2008 14:01 & K & $-0,83$ & $\mathrm{DWH}$ & & & & \\
\hline
\end{tabular}

If trains are delayed by more than 4 minutes and 59 seconds at a measuring point (2 minutes 29 seconds on the Copenhagen Suburban network) the dispatcher creates a Delay Report in the Punctuality Reporting System describing the delay in details (Figure 2). All trains delayed or cancelled because 
of the incident are then attached to the report, both those initially delayed and those consecutively delayed. This process is done manually and relies on the skill and experience of the dispatchers. The trains attached to a report are described as affected trains.

The Delay Reports are coded similar to the UIC leaflet 450-2 [1] and the Delay Reports also receive a responsible party, which is the party that could have prevented the error. Within Rail Net Denmark, the delay code structure is such that a Delay Report unambiguously can be linked to a business unit.

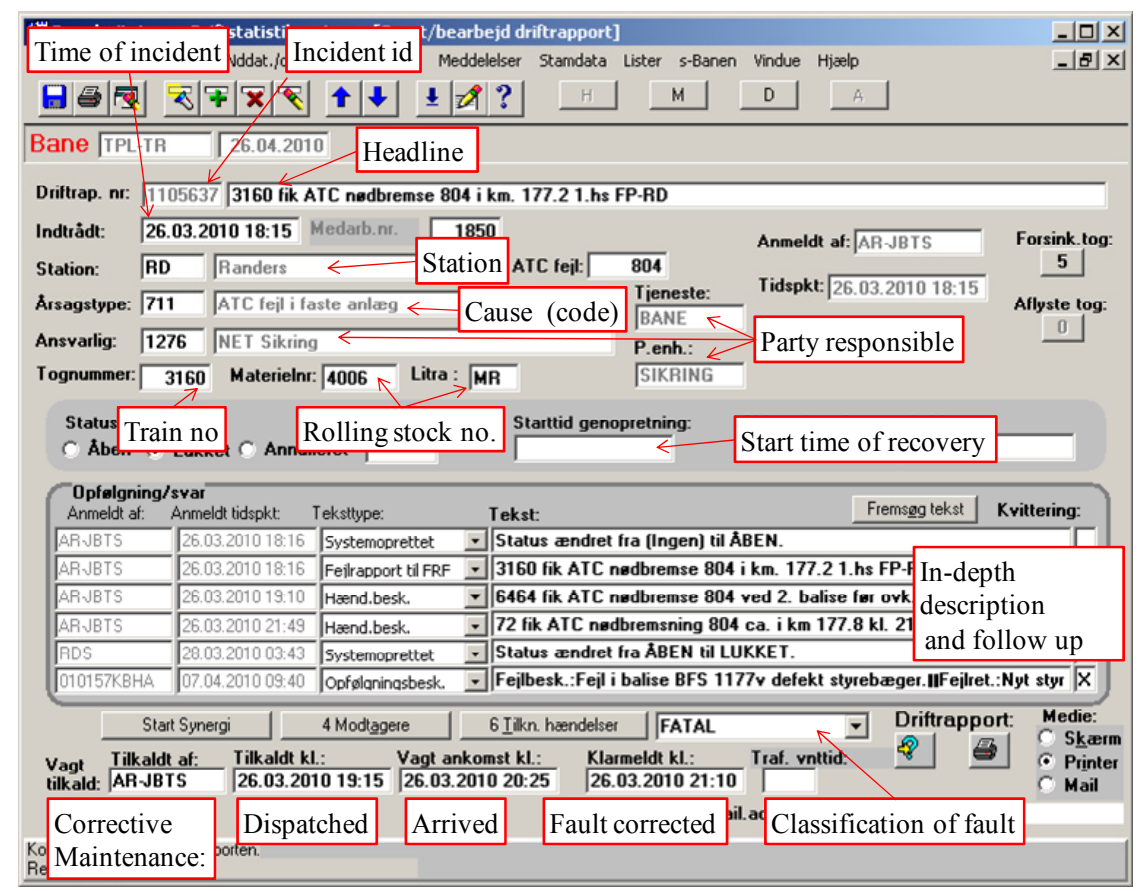

Figure 2: Delay report.

\section{Classical threshold approach to delays analysis}

The primary Key Performance Indicator (KPI) for punctuality within the Danish railway sector is affected trains. Since a responsible party for all affected delays can be indentified through the Delay Reports, a complete KPI system is formed on this basis [6]. Each year, targets for the number of affected trains that Rail Net Denmark is permitted to delay are defined by the Ministry of Transport. Internally in Rail Net Denmark, these targets are broken down into a Punctuality Budget which describes how many trains may be affected by each business unit.

This method has been used for many years, has gradually been perfected and is considered well implemented and well functioning. With some RUs similar targets have been defined including bonus-malus schemes. 
Although the system based on affected train is successful, it has some disadvantages:

- If a train has been gradually delayed, it is attached to the Delays Report describing the cause of and the circumstances surrounding the largest of the delays. Information about the smaller delays is thus lost.

- Minor delays, that never pass the 4 minutes 59 seconds threshold, will go unnoticed using the method of affected trains.

- The focus of the Delay Reports is on where the initial delay occurred and its root causes. There is no focus on where the consecutive delay occurred.

Thus, systemic minor delays with common causes may never be examined, just as the vulnerability of parts of the timetable may never be exposed since there may be many different reasons for the initial delay. Lowering the threshold for Delay Reports will not solve these problems. This will lower the consequences, but require an unrealistic amount of manpower from the dispatchers as well as they may have difficulties determining the actual causes of smaller delays.

Alternative methods such as delay minutes are not used since sufficient detailed passage times can only be obtained from parts of the network. Furthermore, cause of delay is only given to delays of more than 4 minutes and 59 seconds ( 2 minutes and 29 seconds on the Copenhagen Suburban network).

\section{New percentile approach}

To harvest the information about delays that the classical threshold method leaves out, a percentile approach is used on the train run history. For all trains or groups of trains, percentiles of the timetable deviations are calculated for all measuring points over a given period of time (example in Table 2). Alternatively, percentiles are calculated on the timetable deviations between two measuring points (example in Table 3 ).

The distribution function for delays of specific train number is given by

$$
F\left(x_{r, n}\right)=p_{r, n}
$$

where $r$ is the measuring point, $n$ the train number

The corresponding $p$-percentile function is

$$
F^{-1}\left(p_{r, n}\right)=x_{r, n}
$$

The distribution function on group of train numbers is given by

$$
F\left(x_{r, n_{\text {grp }}}\right)=p_{r, n_{\text {grp }}}
$$

where $r$ is the measure point, $n_{g r p}$ the group of trains

The corresponding $p$-percentile function is

$$
F^{-1}\left(p_{r, n_{g r p}}\right)=x_{r, n_{g r p}}
$$

Since eqn. (1) only calculates the deviation for a specific train at a specific measuring point over time, input equals output if the function is only run with 
dataset of one day. A consequence of additional data on which the percentile in eqn. (2) is calculated is that if a single train has a large deviation from the other or if a large deviation exists between the days, this has a greater impact on the result in eqn. (1) than in eqn. (2).

Table 2: $\quad$ Example of meridian on delays at measuring points.

\begin{tabular}{|c|c|c|c|c|}
\hline Train type & Train & Station & Measurement & $\begin{array}{c}\mathbf{5 0 \%} \\
\text { Percentile }\end{array}$ \\
\hline EN & 482 & $\mathrm{KH}$ & Arrival & $-5 \mathrm{~min}$ \\
\hline IC & 132 & $\mathrm{KH}$ & Arrival & $1,17 \mathrm{~min}$ \\
\hline IL & 16 & $\mathrm{KH}$ & Departure & $-3 \mathrm{~min}$ \\
\hline$\varnothing \mathrm{K}$ & 1345 & $\mathrm{KH}$ & Arrival & $0,17 \mathrm{~min}$ \\
\hline$\varnothing \mathrm{K}$ & 1345 & $\mathrm{KH}$ & Departure & $-0,5 \mathrm{~min}$ \\
\hline$\varnothing \mathrm{K}$ & 1345 & $\mathrm{~S} \AA$ & Arrival & $0,67 \mathrm{~min}$ \\
\hline$\varnothing \mathrm{P}$ & 2046 & $\mathrm{G}$ & Departure & $-0,33 \mathrm{~min}$ \\
\hline$\varnothing \mathrm{P}$ & 2046 & $\mathrm{KH}$ & Arrival & $0,5 \mathrm{~min}$ \\
\hline$\varnothing \mathrm{P}$ & 2046 & $\mathrm{SQ}$ & Arrival & $0,33 \mathrm{~min}$ \\
\hline$\varnothing \mathrm{P}$ & 2046 & $\mathrm{~S} \AA$ & Departure & $0,67 \mathrm{~min}$ \\
\hline
\end{tabular}

Table 3: Example of percentiles for deviation between two measuring points.

\begin{tabular}{|c|c|c|c|c|c|c|}
\hline & & \multicolumn{5}{|c|}{ Percentile } \\
\hline Train type & Measurement & $\mathbf{5 0 \%}$ & $\mathbf{7 0 \%}$ & $\mathbf{8 0 \%}$ & $\mathbf{9 0 \%}$ & $\mathbf{9 5 \%}$ \\
\hline IC & SG - SG: station & $\begin{array}{c}0,67 \\
\text { min }\end{array}$ & $\begin{array}{c}0,83 \\
\text { min }\end{array}$ & $\begin{array}{c}1 \\
\text { min }\end{array}$ & $\begin{array}{c}1,17 \\
\text { min }\end{array}$ & $\begin{array}{c}1,66 \\
\text { min }\end{array}$ \\
\hline L & FJ - SO: line & 1 & 1 & 1,17 & 1,17 & 1,34 \\
\hline IC & RG - KY: line & -1 & $-0,83$ & $-0,67$ & $-0,5$ & $-0,17$ \\
\hline L & SNO - MD: line & $-0,83$ & $-0,83$ & $-0,5$ & 0,17 & 1,33 \\
\hline IC & SPR - KØ: line & -1 & $-0,84$ & $-0,83$ & $-0,5$ & $-0,16$ \\
\hline
\end{tabular}

Different percentiles have been used and although all contribute with relevant information, two have proven to be more useful than others: the $50 \%$ percentiles, since this is the meridian and the $90 \%$ percentile since this is the percentile where the poorly performing trains tend to emerge. Comparing the $90 \%$ percentile with the $50 \%$ percentile gives an indication of how much worse the poorly performing trains run.

For the reportings to yield meaningful data, no significant changes may have occurred to the timetable during the period of time examined. Thus the longest period it is possible to examine is the duration of the timetable. If the period examined is too long, issues that have been solved or become irrelevant may still be represented in the data and thus divert focus from present issues. If the period is too short, single events may have too much influence on the result. A guesstimate for the minimum period is a month depending on the number of trains examined and the aim of the analysis. For the majority of the reportings implemented, the optimal time period of evaluation is judged to be one month due to the operational environment that they are being used in.

The percentile approach requires accurate passage times with a high resolution at many measuring points. For many usages, the percentile approach is 
thus only applicable on the parts of the network with automatic collection passage times.

\section{Reportings and results}

Based on the percentile approach, a number of reportings have been developed. They are all based on aggregation of the percentile values using common averages. Common to all these reporting is that they highlight areas which should be analysed in depth by other means before corrective actions can be taken. In many cases, the issues found are well known problems for which no easy solutions are available. The reportings do however quantify the operational impact of the issues found in relation to each other.

\subsection{Worst performing trains}

The best implemented reporting is the list of Worst Performing Trains (Table 4). In this reporting, trains are sorted after their worst meridian for measuring points. Since neighbouring measuring points also tend to have similar values, the 10 worst measuring points are listed in descending order. Only trains where the meridian for the worst measuring point shows a delay of more than 4 minutes and 59 seconds are included. Since the threshold for Delay Reports also is 4 minutes and 59 seconds, it is thus possible to find the reasons for most delays through the Delay Reports. The typical period of time examined is a month and only trains which have been operating on minimum $50 \%$ of the days during the period are included.

Table 4: $\quad$ Worst performing trains.

\begin{tabular}{|c|c|c|c|c|c|c|c|c|}
\hline NR & TRAIN & TYPE & TOP_01 & TOP_02 & TOP_03 & TOP_04 & TOP_05 & RESPONSIBILITY LAST DELAY REPORT \\
\hline 1 & 42703 & HG & $\emptyset$ RE G: $-178,17$ & KLV G: $-177,67$ & HTÅ I: -166 & HIF G: -160 & GL G: -160 & Ekstern: 16 \\
\hline 2 & 38802 & HG & PHM G: $-119,33$ & TRK G: $-110,83$ & HH G: $-110,17$ & CPH G: $-110,17$ & RO G: -110 & Ekstern: 12 | HECTORRAIL, Hectorrail: 3 \\
\hline 3 & 44735 & GD & VK G: -91 & PAI: -90 & OJ G: $-79,33$ & TE G: $-78,83$ & FZ G: $-78,83$ & Ekstern: 16 | RAILION, Railion: 4 \\
\hline 4 & 42738 & GD & TRK G: $-73,33$ & RO G: $-72,17$ & HH G: $-71,67$ & BO G: $-71,5$ & VY G: $-71,33$ & Ekstern: 13 | RAILION, Railion: 4 | BANE, Proj \\
\hline 5 & 44748 & GD & CPH G: $-72,5$ & VM G: $-67,83$ & FZ G: $-67,5$ & LK G: -67 & KD G: $-66,17$ & Ekstern: 10 | RAILION, Railion: 2 | BANE, Sikri \\
\hline 6 & 44721 & GD & TE G: $-64,33$ & OJ G: -64 & RQ G: $-63,83$ & SST G: -63 & VK I: $-62,5$ & Ekstern: 18 | RAILION, Railion: 4 | BANE, Proj \\
\hline 7 & 42737 & GD & VK I: $-61,83$ & VK U: $-60,5$ & OJ G: $-60,33$ & TE G: -60 & SST G: -60 & Ekstern: 10 | BANE, Sikring: 1 | RAILION, Raili \\
\hline 8 & 42735 & GD & VK G: $-41,5$ & PA I: -40 & TE G: $-39,5$ & KØ G: -39,17 & RQ G: $-38,5$ & Ekstern: 11 | RAILION, Railion: 4 | DSB, Passa \\
\hline 9 & 44709 & GD & RQ G: - 35 & TE G: $-33,67$ & VK G: $-33,5$ & PAI: -32 & SNO G: $-30,5$ & Ekstern: 13 | RAILION, Railion: 3 | BANE, Fjer \\
\hline 10 & 46256 & GX & PA I: -30 & SO G: -6 & RG I: -6 & FJ G: $-5,5$ & SG G: -5 & Ekstern: 12 | RAILION, Railion: 1 \\
\hline 11 & 482 & EN & KA G: -27 & EB I: -26 & MD G: -26 & KD I: $-25,5$ & KD U: $-24,33$ & Ekstern: 19 | DSB, Drift: 1 | RAILION, Railion: \\
\hline 12 & 44731 & GD & PA U: -27 & TE I: -19 & OJ G: $-17,33$ & RQ G: $-16,33$ & SST G: -16 & Ekstern: 9 | BANE, Projekt: 6| RAILION, Railid \\
\hline 13 & 44707 & GD & FJ G: -25 & SO G: $-24,67$ & RG G: -24 & SG G: $-23,83$ & FO G: -23 & Ekstern: 15 | RAILION, Railion: 2 | BANE, Spon \\
\hline 14 & 44722 & GD & PHM G: $-20,83$ & CPH I: $-19,67$ & TÅT G: $-18,83$ & KLV G: $-17,83$ & IG G: $-15,17$ & Ekstern: 12 | RAILION, Railion: 5 | BANE, Sikri \\
\hline 15 & 44732 & GD & TÅT G: $-20,33$ & KLV G: -20 & CPH I: $-19,67$ & IG G: -19 & TRK G: $-18,83$ & Ekstern: 9 | RAILION, Railion: 4 | BANE, Proje \\
\hline 16 & 9229 & G & BO G: $-14,67$ & SO G: $-14,33$ & KY G: $-14,33$ & VY G: -14 & RG G: -14 & RAILION, Railion: 10 | DSB, Fføst: 2 | BANEP, \\
\hline 17 & 33 & IE & RFI: -12 & RF U: -10 & NFI: -8 & TRK G: $-3,17$ & NF U: -3 & Ekstern: 18 | DSB, Fføst: 1 | DSB, Togsæt: 1 \\
\hline 18 & 44718 & GD & MV G: $-11,5$ & UV G: $-10,83$ & JU G: $-10,33$ & NG I: -10 & OD G: -10 & Ekstern: 7 | RAILION, Railion: 3 | BANE, Proje \\
\hline 19 & 40008 & GK & PA I: -11 & RQ G: $-2,83$ & TL I: -2 & KD G: -2 & VM G: -2 & Ekstern: 10 \\
\hline 20 & 38851 & GD & VK G: $-10,33$ & OJ G: -10 & TE G: -10 & RQ G: $-9,83$ & SST G: $-9,33$ & Ekstern: 6 | BANE, Projekt: 5 | RAILION, Railid \\
\hline 21 & 44737 & GD & TE G: $-9,33$ & VK I: $-8,5$ & VK U: $-6,83$ & PAI: -6 & SST G: -5 & Ekstern: 5 | RAILION, Railion: 5 | BANE, Sikrin \\
\hline 22 & 910 & IC & KN U: $-9,17$ & $\mathrm{KH} \mathrm{I}:-9$ & KN I: $-8,17$ & KH U: -8 & KK I: -8 & DSB, Passager: 4 | Ekstern: 4 | BANE, Sikring: \\
\hline 23 & 9424 & G & HTÅ I: $-8,83$ & GL I: -6 & TRK G: $-5,33$ & RO G: -4 & RG U: -4 & RAILION, Railion: 10 | BANE, Sikring: 2 | CFL \\
\hline 24 & 60044 & $\mathrm{M}$ & CPH I: $-8,5$ & TÅT G: $-7,5$ & KLV G: $-6,83$ & KH U: -6 & & DSB, Togsæt: 4 | BANE, Spor: 2 | Ekstern: 2 | \\
\hline 25 & 7515 & G & FA U: -8 & BK G: $-3,33$ & BET G:,- 83 & VJI: -,17 & HR I: 0 & RAILION, Railion: 13 \\
\hline 26 & 1516 & $\mathrm{R} \emptyset$ & KN U: -8 & KN I: $-7,33$ & KKI: -7 & HGL I: $-5,5$ & KK U: $-5,5$ & DSB, Togsæt: 3 | Ekstern: 3 | BANE, Sikring: 2 \\
\hline 27 & 381 & IE & OJ G: $-7,5$ & TE G: $-6,83$ & VK I: $-6,33$ & SST G: $-6,17$ & RQ G: $-5,33$ & DSB, Passager: 4 | DSB, Togsæt: 4 | BANE, Sik \\
\hline 28 & 2218 & $\mathrm{R} \varnothing$ & KN U: $-7,5$ & KK I: $-6,67$ & KH I: $-6,5$ & KH U: $-6,5$ & KN I: $-6,33$ & \begin{tabular}{|l|l|l|} 
DSB, Lok-Vogne: 4 | Ekstern: 4 | BANE, Spor: \\
\end{tabular} \\
\hline
\end{tabular}


Since the summer of 2009, the reporting of the Worst Performing Trains has been carried out on a monthly basis. The reporting is distributed internally to the timetabling section, amongst management and externally to RUs with the expectation that all parties attempt to locate the root causes for the delays and act accordingly. The list of Worst Performing Train plugs the gap in the Plan - Do Check - Act circle. Until this reporting was implemented, there was no formal systematic feedback loop in the timetabling process [7].

The initial experience is that in most cases, the list reveals no major surprises. There are in most cases well know explanations for why trains are on the list. These may be that the trains are freight trains (different nature of operation), running during the night and technically delayed by planned system possessions (Rail Net Denmark uses system possessions on the busiest part of the network) or trains arriving late to the Danish Railway Network from abroad.

Even if there are well-known reasons that are difficult to resolve for the trains being on the list, the list of Worst Performing Train quantifies the performance of each train in relation to the other trains as well as in absolute terms. E.g. on one railway line the 2010 timetable works much better than the 2009 timetable in terms of systematic delays. This manifests itself by noticeably fewer trains from that line being on the list in 2010 compared to in 2009.

Even though the list of Worst Performing Trains has been generally accepted, the implementation and use still merits more analysis and actions. Or as the head of the timetabling section concluded: "The list of Worst Performing Trains contains lots of yet unharvested information".

\subsection{Loss of time on open line}

The Loss of Time on Open Line method (Figure 3) is also a well implemented reporting. Here different percentiles for loss or gain of time on open line are calculated for a group of trains over a period of time.

Typically the $50 \%, 70 \%, 80 \%, 90 \%$ and $95 \%$ percentiles are calculated. The $50 \%$ percentile in Loss of Time on Open Line reporting is generally either due to local speed restrictions or technical properties of the measuring points (halts) while the $90 \%$ percentile is where poorly running trains typically begin to create delay-peaks. Peaks at lower percentiles indicate factors which are common for all trains, e.g. local speed restrictions whereas peaks at higher percentiles indicate factors which can be isolated to one or a few trains e.g. timetable conflicts or train traction power problems.

On top-managerial levels, this reporting has been used to focus the attention on the reason behind delay or as a senior Rail Net Denmark manager once concluded "if the $50 \%$ best running trains can keep the schedule, the problem cannot be the infrastructure". The Loss of Time on Open Line reporting is used ad hoc when in-depth analysis is need of lines.

The overall development in the performance of products on a line can be illustrated calculating the average loss of time between measurement points for the different percentiles over a given period of time (Figure 4). Such an aggregation will only reveal information on a much aggregated level, which allows general trends to emerge. 


\section{København - Århus}

July 2009 - $50 \%$ percentile for loss of time on open line

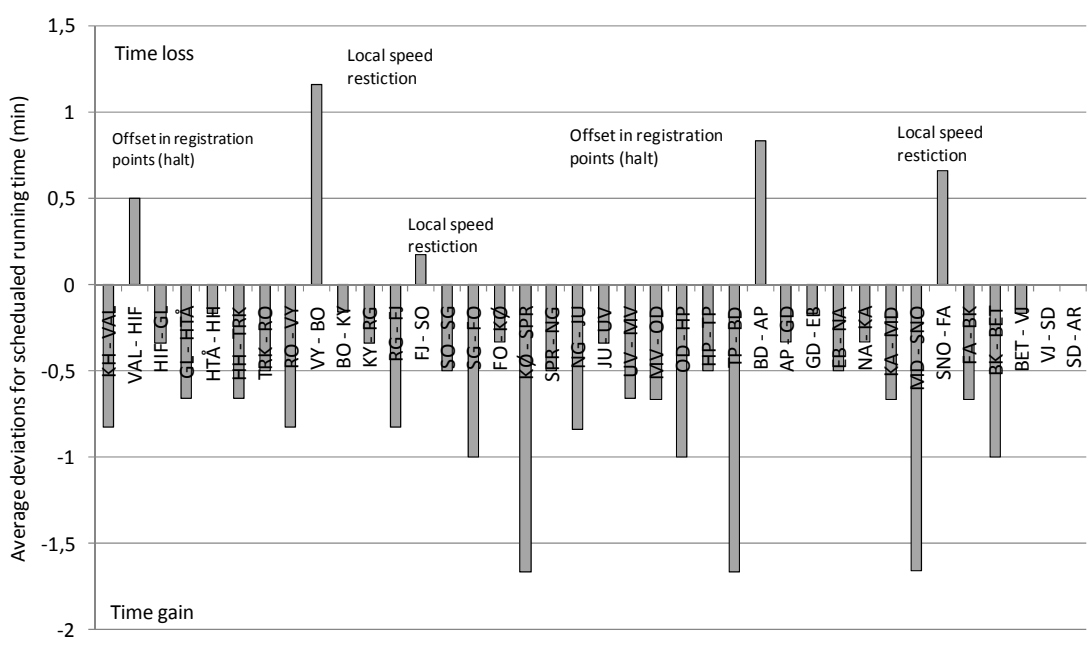

Figure 3: $\quad$ Example of loss of time on open line.

\section{Distribution of percentile for loss of time on open line KH-AR}

Fast trains towards København

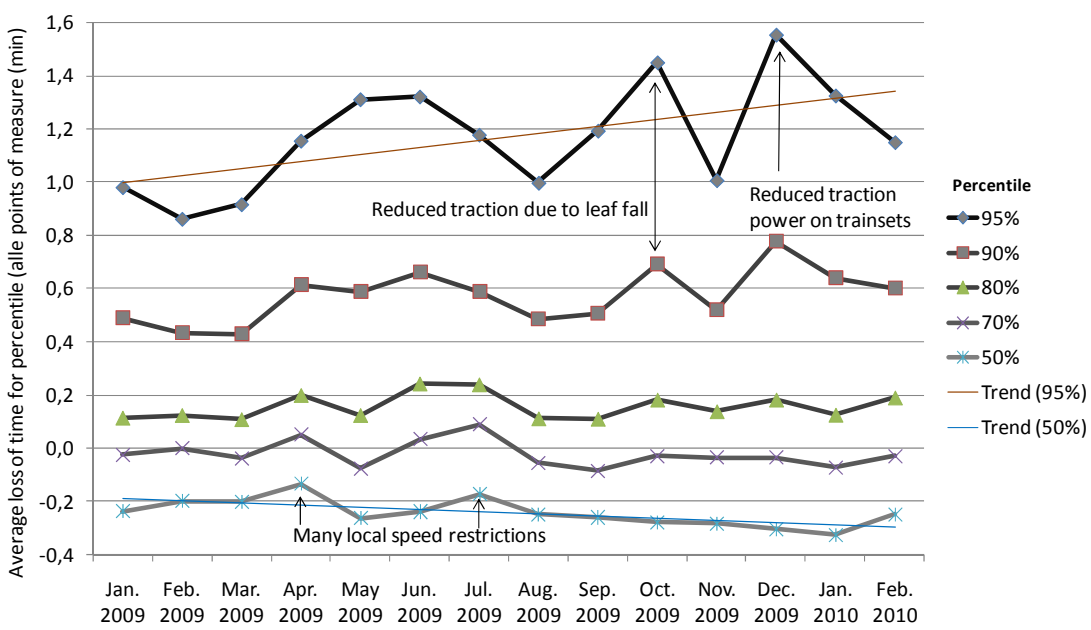

Figure 4: Development in percentile for loss of time on open line.

An aggregated reporting can also be used to evaluate the difference in performance between different train products. The timetable for the rush hour train in Figure 5 is very ambitious which clearly shows. 


\section{Percentile distribution of trainruns on open line for rushhour trains and stop trains on line segment $\mathrm{KH}-\mathrm{NI}$ on weekdays}

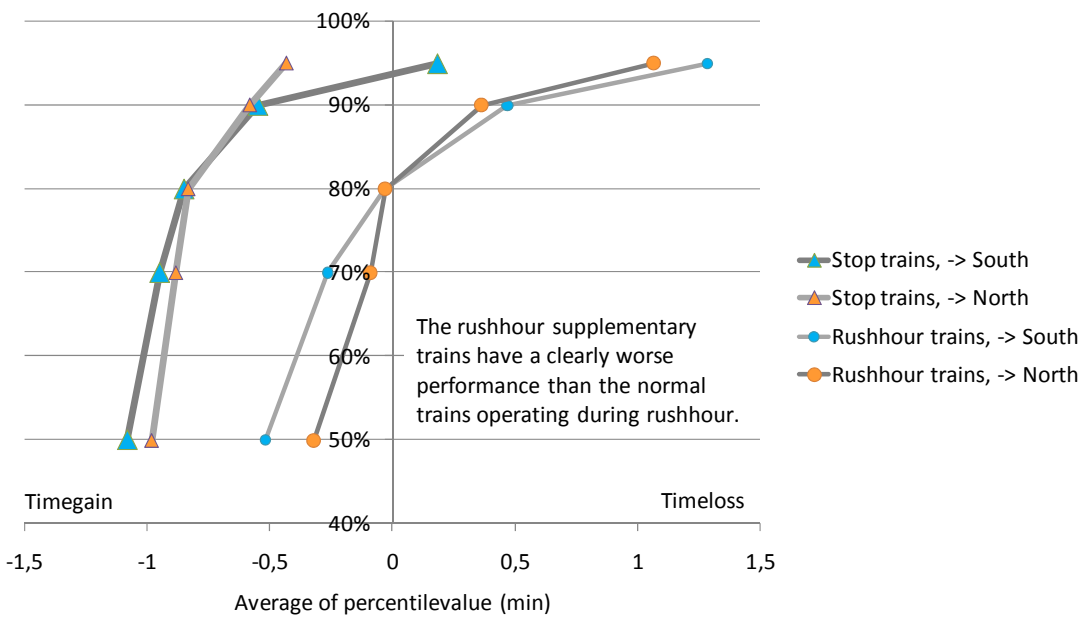

Figure 5: Comparison between train products.

\subsection{Realised timetable}

The newest reporting is the Realised Timetable reporting. In this reporting, the meridian of the timetable deviation at a number of measure points for trains is plotted for each train as a realised timetable.

Table 5: $\quad$ Realised timetable.

Medrian for schedual deviation for passage times during March 2010, weekdays.

\begin{tabular}{|c|c|c|c|c|c|c|c|c|c|c|c|c|c|}
\hline \multicolumn{2}{|l|}{ Scheduale } & Station $->$ & \multicolumn{2}{|l|}{ HTA } & \multirow{2}{*}{\begin{tabular}{|l|} 
GL \\
Pass \\
\end{tabular}} & \multirow{2}{*}{\begin{tabular}{|l|} 
HIF \\
Pass \\
\end{tabular}} & \multicolumn{2}{|l|}{ VAL } & \multicolumn{2}{|l|}{$\mathrm{KH}$} & \multicolumn{2}{|l|}{$\mathrm{KN}$} & \multirow{2}{*}{\begin{tabular}{|l|} 
KK \\
Arrival \\
\end{tabular}} \\
\hline Dep HTA & Headway & Train & Arrival & Dep & & & Arrival & Dep & Arrival & Dep & Arrival & Dep & \\
\hline \begin{tabular}{|l|}
$08: 43: 00$ \\
\end{tabular} & & 2512 & 1,0 & $-0,7$ & 0,2 & 0,0 & $-0,3$ & $-2,0$ & $-2,0$ & $-1,8$ & $-1,8$ & $-2,8$ & $-2,0$ \\
\hline \begin{tabular}{|l|}
$08: 48: 00$ \\
\end{tabular} & $5 \mathrm{~min}$ & 1512 & $-0,2$ & $-1,0$ & $-0,2$ & 0,3 & & $-1,0$ & $-2,3$ & $-3,0$ & $-3,5$ & $-4,5$ & $-4,8$ \\
\hline \begin{tabular}{|l|}
$08: 50: 00$ \\
\end{tabular} & $2 \min$ & 4210 & $-0,2$ & $-0,8$ & 0,0 & 0,3 & 0,7 & $-1,0$ & $-1,7$ & & & & \\
\hline \begin{tabular}{|l|}
$08: 53: 00$ \\
\end{tabular} & $3 \min$ & 44718 & $-2,3$ & $-1,0$ & 0,7 & 1,3 & & & & & & & \\
\hline 08:58:00 & $5 \mathrm{~min}$ & 8114 & $-2,5$ & $-4,0$ & $-2,5$ & $-2,3$ & & $-2,2$ & $-4,0$ & $-4,0$ & $-4,7$ & $-5,5$ & $-6,0$ \\
\hline \begin{tabular}{|l|} 
09:00:00 \\
\end{tabular} & $2 \min$ & 4112 & $-2,2$ & $-2,3$ & $-1,7$ & $-2,0$ & $-1,0$ & $-2,5$ & $-2,7$ & $-0,5$ & $-2,3$ & $-3,3$ & $-2,3$ \\
\hline \begin{tabular}{|c|}
$09: 06: 00$ \\
\end{tabular} & $6 \mathrm{~min}$ & 108 & $-1,2$ & $-2,3$ & $-1,5$ & $-1,5$ & & $-2,0$ & $-3,7$ & $-2,2$ & & & \\
\hline \begin{tabular}{|l|}
$09: 10: 00$ \\
\end{tabular} & $4 \min$ & 10 & $-2,2$ & $-3,5$ & $-2,5$ & $-2,2$ & & $-4,0$ & $-3,7$ & & & & \\
\hline \begin{tabular}{|l|} 
09:13:00 \\
\end{tabular} & $3 \mathrm{~min}$ & 4514 & $-0,7$ & $-2,2$ & $-1,5$ & $-1,5$ & $-1,0$ & $-2,5$ & $-3,2$ & $-1,7$ & $-1,7$ & $-3,0$ & $-2,7$ \\
\hline \begin{tabular}{|c|}
$09: 17: 00$ \\
\end{tabular} & $4 \mathrm{~min}$ & 8214 & $-2,7$ & $-3,3$ & $-2,7$ & $-3,0$ & $-2,2$ & $-3,8$ & $-3,3$ & $-3,5$ & $-3,0$ & $-4,2$ & $-3,5$ \\
\hline \begin{tabular}{|l|}
$09: 23: 00$ \\
\end{tabular} & $6 \mathrm{~min}$ & 8314 & & $-3,7$ & $-3,8$ & $-4,3$ & & $-3,0$ & $-6,8$ & & & & \\
\hline \begin{tabular}{|c|}
$09: 28: 00$ \\
\end{tabular} & $5 \mathrm{~min}$ & 16 & & $-1,7$ & $-0,5$ & 0,2 & & 0,5 & $-3,0$ & $-3,0$ & & & \\
\hline \begin{tabular}{|l|}
$09: 30: 00$ \\
\end{tabular} & $2 \min$ & 4114 & $-2,7$ & $-3,0$ & $-2,2$ & $-2,7$ & $-1,8$ & $-3,3$ & $-5,2$ & $-3,0$ & $-2,0$ & $-3,0$ & $-3,0$ \\
\hline \begin{tabular}{|l|}
$09: 35: 00$ \\
\end{tabular} & $5 \mathrm{~min}$ & 910 & $-2,7$ & $-3,7$ & $-3,0$ & $-3,5$ & $-4,7$ & $-6,0$ & $-9,0$ & $-8,0$ & $-8,2$ & $-9,2$ & $-8,0$ \\
\hline \begin{tabular}{|c|}
$09: 43: 00$ \\
\end{tabular} & $8 \mathrm{~min}$ & 2516 & 1,2 & $-1,0$ & $-0,3$ & $-0,2$ & 0,2 & $-1,5$ & $-4,2$ & $-3,5$ & $-3,3$ & $-4,0$ & $-3,2$ \\
\hline \begin{tabular}{|c|}
$09: 48: 00$ \\
\end{tabular} & $5 \mathrm{~min}$ & 1516 & $-0,3$ & $-1,5$ & $-0,5$ & $-0,3$ & & $-2,0$ & $-5,2$ & $-5,0$ & $-7,3$ & $-8,0$ & $-7,0$ \\
\hline \begin{tabular}{|c|}
$09: 58: 00$ \\
\end{tabular} & $10 \mathrm{~min}$ & 1218 & 0,0 & $-1,0$ & 0,0 & $-0,2$ & & $-1,0$ & $-4,0$ & $-3,2$ & $-3,0$ & $-4,0$ & $-3,7$ \\
\hline \begin{tabular}{|l|}
$10: 00: 00$ \\
\end{tabular} & $2 \min$ & 4116 & $-0,8$ & $-2,0$ & $-0,7$ & $-1,0$ & $-0,2$ & $-1,8$ & $-2,3$ & $-0,2$ & $-1,3$ & $-2,2$ & $-1,2$ \\
\hline \begin{tabular}{|l|}
$10: 06: 00$ \\
\end{tabular} & $6 \mathrm{~min}$ & 114 & $-1,2$ & $-2,3$ & $-1,3$ & $-3,2$ & & $-3,2$ & $-6,2$ & $-3,7$ & & & \\
\hline \begin{tabular}{|l|}
$10: 10: 00$ \\
\end{tabular} & $4 \mathrm{~min}$ & 14 & 0,0 & $-1,0$ & 0,2 & 0,5 & & $-3,0$ & $-6,5$ & & & & \\
\hline \begin{tabular}{|l|}
$10: 13: 00$ \\
\end{tabular} & $3 \min$ & 4518 & $-1,5$ & $-2,5$ & $-2,0$ & $-1,7$ & $-1,2$ & $-2,8$ & $-3,0$ & $-3,7$ & $-3,2$ & $-3,8$ & $-2,8$ \\
\hline \begin{tabular}{|l|}
$10: 17: 00$ \\
\end{tabular} & $4 \mathrm{~min}$ & 2218 & $-3,7$ & $-4,3$ & $-3,3$ & $-4,0$ & $-3,0$ & $-4,3$ & $-4,0$ & $-4,5$ & $-6,0$ & $-7,0$ & $-6,5$ \\
\hline \begin{tabular}{|l|}
$10: 30: 00$ \\
\end{tabular} & $13 \mathrm{~min}$ & 4018 & 0,2 & $-0,7$ & 0,3 & 0,2 & 1,0 & $-0,5$ & $-0,8$ & 1,8 & 1,0 & 0,3 & 0,8 \\
\hline \begin{tabular}{|c|}
$10: 35: 00$ \\
\end{tabular} & $5 \mathrm{~min}$ & 812 & $-0,2$ & $-1,3$ & $-0,7$ & $-1,5$ & $-0,8$ & $-2,5$ & $-3,7$ & $-3,0$ & $-1,7$ & $-2,7$ & $-1,5$ \\
\hline
\end{tabular}


This reporting is used to do an in depth analysis of a network section. The aim is to illustrate which trains often run late and whether this causes consecutive delays to other trains. E.g. in Table 5, train 8114 leaves HTA with a delay of 5 minutes or more during more than half the days, which causes consecutive delays for the next 6 trains. Train 2218 seems also to be performing poorly, but since there are no trains scheduled to run just after this, this trains does not cause consecutive delays to other trains. An in-depth analysis of the neighbouring network sections is to be carried out to determine where in the network the delays of train 8114 originate.

This reporting is currently being used to analyse the traffic around Copenhagen where there are problems with consecutive delays due to dense traffic.

\subsection{Perspective and results obtained}

The percentile approach has been used for around a year and has yielded new information in new reportings. The reportings presented in this paper are the most successful in Rail Net Denmark to date but more will be developed depending on the demands.

Fundamentally, four different methods can be used when aggregating the data

- Isolating the trains or groups of trains

The list of Worst Performing Trains is an example of this (Table 4).

- Isolating the geography

The Loss of Time on Open Line is an example of this (Figure 3).

- Isolating the time period

- Isolating the percentile

The methods may be combined depending on the requirement. The realised timetable (Table 5) and the two distributions of percentiles (Figures 4 and 5) are examples of combinations of these different aggregations.

An issue to be investigated is at what percentile, the poorly performing trains begin to emerge, how constant this value is and what information can be deducted from these analysis. Presently, it appears that this happens around the $90 \%$ percentile. Examination of the distribution of delays versus percentiles should also be carried out to yield information on what is "best practice" and what can be considered as poor performances. An academic vision is to develop a timetable quality measure describing the trains' ability to stay punctual and the ability to recover after disruptions.

\section{Organisational implementation}

Though successful, the percentile approach cannot replace the present affected train KPIs, and should not be considered as a replacement either. The approach is orthogonal yielding new additional information. The approach is not an advanced theoretical statistics approach either but a hands-on approach born out of requirements from an operations environment. 
The development and implementation process can be described as a push-pull approach. Pull because there has been a general company-wide requirement for more information describing performance shortfalls and push because no-one had previously requested reportings based on a percentile approach.

The success experienced with the percentile approach is due to more advanced analysis being able to deliver answers to questions already posed in the organisation. The success is also due to the top management being very data- and KPI oriented and thus promoting a corporate mindset welcoming more advanced reportings.

\section{Conclusion}

Analysing all timetable deviations with a percentile approach and not only those above a predefined threshold yields valuable new information. The delay percentiles can be aggregated on train numbers (or groups of trains), geography (measuring points), time period, percentile or as a combination. A number of reportings have been developed helping Rail Net Denmark locate systematic causes for delays. These can be used to achieve a better punctuality.

The percentile approach is orthogonal to the classical analysis of cause of delay above a threshold and should not be regarded as a substitute but as a valuable supplement.

The organisational implementation and acceptance is essential. The success of the percentile approach is amongst others an emerging need for more advanced analysis as well as a general shift in the corporate mindset towards a higher KPI focus.

\section{References}

[1] UIC, Assessment of the performance of the network related to rail traffic operation for the purpose of quality analysis - delay coding and delay cause attribution process (UIC leaflet 450-2), International Union of Railways (UIC), Paris, France, 2009.

[2] Rail Net Denmark, Network statement 2010, 2009.

[3] Landex, A. Methods to estimate railway capacity and passenger delays, Ph.D. thesis, DTU Transport 2008.

[4] Homepage of Rail Net Denmark, www.bane.dk, 1/5/2010.

[5] UIC, Capacity (UIC leaflet 406), International Union of Railways (UIC), Paris, France, 2004.

[6] Richter, T. A better railway through higher delay data quality (En bedre jernbane gennem højere datakvalitet), Annual Transport Conference at Aalborg University 2008. (In Danish).

[7] Schittenhelm, B., Richter, T., Railway Timetabling Based on Systematic Follow-up on Realized Railway Operations, Annual Transport Conference at Aalborg University 2009. 